CARDIOVASCULAR MEDICINE

\title{
Impairment of cardiopulmonary receptor sensitivity in the early phase of heart failure
}

\author{
P A Modesti, G Polidori, I Bertolozzi, S Vanni, I Cecioni
}

Heart 2004;90:30-36

See end of article for authors' affiliations

.....................

Correspondence to: Professor Pietro A Modesti, Clinica Medica e

Cardiologia, University of Florence, Viale Morgagni 85,50134 Florence, Italy; pa.modesti@dfc.unifi.it

Accepted 29 May 2003
Objectives: To characterise the efficiency of the cardiopulmonary baroreflex system in the early phase of heart failure and its relation to limitation of physical activity.

Design: Forearm blood flow (venous occlusion plethysmography), vascular resistance, and central venous pressure (CVP), estimated from an antecubital vein, were measured in the supine position at baseline and 15 minutes after application of lower body negative pressure at -7 and $-14 \mathrm{~mm} \mathrm{Hg}$ (receptor downloading) or leg raising (receptor loading).

Subjects: Heart failure patients without limitation (NYHA class I; $n=18$ ) or with slight limitation of physical activity (NYHA class $I ; n=13$ ), and 11 healthy controls.

Results: The efficiency of the cardiopulmonary baroreflex function, expressed by the slope of the relation between CVP changes and the corresponding changes of calculated forearm vascular resistance (gain), was reduced both in NYHA class I patients (mean (SD) $-1.99(0.83) v-2.78(0.66)$ in controls; $\mathrm{p}<0.05$ ) and NYHA class II patients $(-1.29$ (0.5); $<<0.001 v$ controls). However, change in peripheral vascular resistance during preload increase was similar in controls (-3.3 (0.9) units) and in NYHA class I patients (-3.3 (2.1) units; NS $v$ controls), and was significantly reduced only in NYHA class II patients $(-1.6(1.3)$ units, $p<0.03 v$ controls). The gain in the cardiopulmonary reflex was related to the distance walked during the six minute corridor test.

Conclusions: A reduced tonic efficacy of the cardiopulmonary reflex system is already detectable in the early phase of heart failure, the impairment in acute response to preload increase being detectable only in symptomatic patients. t is now well recognised that sympathetic nervous system activation occurs early in the natural history of heart failure $^{12}$ and increased regional adrenergic drive precedes the generalised sympathetic activation of advanced heart failure..$^{3-5}$ However, the event responsible for the impaired autonomic adjustments in the early phase of heart failure is still debated. ${ }^{6-9}$

A defective arterial baroreceptor inhibitory influence on heart rate and sympathetic nerve traffic has been found in the early phase of heart failure (New York Heart Association (NYHA) functional class I and II). ${ }^{1}$ The arterial baroreflex system is the most rapidly responding of the regulatory systems for buffering fluctuations in blood pressure, but is characterised by an acute resetting of the afferent nerve discharge and efferent sympathetic nerve activity, with a shift of the baroreceptor curve in the direction of the prevailing pressure. The long term adaptation of blood volume is buffered by cardiopulmonary baroreceptor reflexes, the mechanoceptors for which are located in the cardiac wall. ${ }^{10} 11$ This low pressure system provides tonic restraint of the sympathetic efferent activity to the peripheral vessels and responds to cardiac filling pressure changes by activating reflexes that modify regional vascular resistance, blood distribution, and cardiac output. Cardiopulmonary receptors are tonically active, the physiological response to their stimulation being less powerful than the arterial receptor response but more prolonged. ${ }^{10} 11$

Cardiopulmonary baroreceptor reflexes are impaired in patients with severe heart failure (NYHA classes III and IV) (12-15 $^{15}$ but no studies have been done in the early phase of the disease, where an impaired cardiopulmonary reflex system might be involved in the increased adrenergic drive at rest. In addition, a defective cardiopulmonary reflex mediated peripheral adaptation to preload increase might also play a role in the reduced adaptation to physical activity and could cause a discrepancy between functional class and cardiac function.

We undertook the present study to investigate the efficiency of the cardiopulmonary reflex system in patients with cardiac disease without limitation of physical activity (NYHA class I) and with slight limitation of physical activity (NYHA class II).

\section{METHODS}

\section{Subjects investigated}

We investigated 31 patients (mean (SD) age 67 (10) years) with heart failure caused by ischaemic dilated cardiomyopathy, and 11 healthy controls. The diagnosis of ischaemic dilated cardiomyopathy was based on clinical and echocardiographic examination, cardiac catheterisation, and coronary angiography. Heart failure was diagnosed according to the definition approved by the European Society of Cardiology ${ }^{16}$ - that is, the presence of symptoms of heart failure either at rest or during exercise and objective evidence of cardiac dysfunction at rest. Inclusion criteria were the presence of regional wall motion abnormalities caused by previous myocardial infarction, a left ventricular end diastolic diameter of $\geqslant 55 \mathrm{~mm}$, or an echocardiographic left ventricular ejection fraction of $\leqslant 50 \%$. Patients with aortic valve disease or congenital heart disease, hypertension, a recent history of effort angina, unstable angina, recent myocardial

\footnotetext{
Abbreviations: ANP, atrial natriuretic peptide; AVP, arginine vasopressin, BNP, brain natriuretic peptide; CVP, central venous pressure; LBNP, lower body negative pressure; NYHA, New York Heart Association; PRA, plasma renin activity
} 
infarction (within six months of the study), renal failure, alteration of urinalysis, abnormal liver function test, diabetes, or malignancy were excluded.

Heart failure was classified according to the NYHA functional class. ${ }^{17}$ Eighteen patients had no limitation in physical activity despite the presence of heart disease (class I), whereas 13 had mild limitation of activity (class II).

All subjects gave their written informed consent to their participation in the study.

In all subjects echocardiographic measurements were done prospectively. Measurements were calculated according to the recommendations of the American Society of Echocardiography. ${ }^{18}$ Cardiac output was measured by the formula CSA $\times$ VTI $\times$ HR, where CSA is the aortic cross sectional area, VTI is the systolic velocity integral, and HR is the heart rate. ${ }^{19}$ Diastolic relaxation was assessed by Doppler evaluation of the early maximum (E) and atrial (A) left ventricular filling inflow velocities and their ratio (E/A). Echocardiographic measurements were read independently by two observers unaware of the patients' identities. Mean (SD) interobserver and intraobserver variabilities were $4.1(0.5) \%$ and $2.5(0.3) \%$ for cavity size and $3.7(0.4) \%$ and $2.1(0.3) \%$ for wall thickness, respectively.

Functional capacity was assessed by the six minute walk test. The test was done in an indoor corridor, $25 \mathrm{~m}$ long, according to the suggestions of Guyatt and colleagues. ${ }^{20}$ Briefly subjects were asked to walk the corridor at a rapid rate from one end to the other, and after six minutes the physician measured the distance walked. Repeatability was assessed by doing the test twice in the same day.

The demographic and clinical characteristics of subjects investigated are given in table 1.

\section{Experimental procedures}

Drug treatment, including angiotensin converting enzyme inhibitors, was discontinued at least two weeks before the study. During the week preceding the study all the subjects consumed a normal sodium diet $(108 \mathrm{mmol} / \mathrm{day})$. Alcohol, caffeine, cigarettes, and physical exercise were prohibited within 24 hours of the study.

Table 1 Echocardiographic and haemodynamic characteristics of the subjects investigated

\begin{tabular}{llll}
\hline & $\begin{array}{l}\text { Controls } \\
(\mathbf{n}=11)\end{array}$ & $\begin{array}{l}\text { NYHA I } \\
(\mathbf{n}=18)\end{array}$ & $\begin{array}{l}\text { NYHA II } \\
(\mathbf{n}=13)\end{array}$ \\
\hline Age (years) & $53(10)$ & $57(11)$ & $59(8)$ \\
Left atrium (mm) & $35(4)$ & $40(4)^{*}$ & $43(5)^{*}$ \\
Septum (mm) & $9.3(1.0)$ & $9.9(0.8)$ & $9.7(0.9)$ \\
Posterior wall (mm) & $9.3(0.8)$ & $9.8(0.7)$ & $9.5(0.7)$ \\
LVSD (mm) & $32(2)$ & $37(5)^{*}$ & $45(8)^{*}+$ \\
LVDD (mm) & $50(2)$ & $55(7)^{*}$ & $60(7)^{*}$ \\
RWT & $0.37(0.03)$ & $0.37(0.05)$ & $0.32(0.05)^{*} \dagger$ \\
LVM (g) & $115(18)$ & $140(23)^{*}$ & $161(41)^{*}$ \\
ESS (kdyne/cm $)$ & $67(6)$ & $88(22)^{*}$ & $124(46)^{*} \dagger$ \\
LVEF (\%) & $65(5)$ & $55(7)^{*}$ & $43(8)^{*} \dagger$ \\
Vcf (s $\left.{ }^{-1}\right)$ & $1.21(0.04)$ & $1.05(0.13)^{*}$ & $0.87(0.21)^{*} \dagger$ \\
Fractional shortening & $36(2)$ & $32(3)^{*}$ & $26(7)^{*} \dagger$ \\
(\%) & & & \\
E/A ratio & $1.38(0.25)$ & $1.02(0.39)^{*}$ & $0.76(0.25)^{*} \dagger$ \\
PRA (ng/ml/h) & $0.7(0.6)$ & $1.0(0.6)$ & $1.1(0.9)$ \\
AVP (pg/ml) & $1.1(0.7)$ & $1.2(0.7)$ & $1.6(0.9)$ \\
ANP (pg/ml) & $13(6)$ & $19(11)$ & $70(29)^{*} \dagger$ \\
BNP (pg/ml) & $26(13)$ & $30(14)$ & $69(34)^{*} \dagger$ \\
\hline
\end{tabular}

${ }^{*} \mathrm{p}<0.05 v$ controls; $\uparrow \mathrm{p}<0.05 v \mathrm{NYHA}$ class I at multiple comparison test. ANP, atrial natriuretic peptide; AVP, arginine vasopressin; BNP, brain natriuretic peptide; ESS, end systolic stress; LVDD, left ventricular diastolic diameter; LVEF, left ventricular ejection fraction; LVM, left ventricular mass; LVSD, left ventricular systolic diameter; NYHA, New York Heart Association functional class; PRA, plasma renin activity; RWT, relative wall thickness; Vcf, mean velocity of circumferential fibre shortening.
All the subjects had a similar basic diet containing a constant amount of protein $(1.3 \mathrm{~g} / \mathrm{kg})$, energy $(126 \mathrm{~kJ} / \mathrm{kg})$, calcium $(800 \mathrm{mg} / 24 \mathrm{~h})$, sodium ( $108 \mathrm{mmol} / \mathrm{day})$, and potassium $(80 \mathrm{mmol} / \mathrm{day})$. The patients completed the study protocol (lower body negative pressure (LBNP) plus leg raising plus cold pressor test) on two consecutive days.

Patients and control subjects came to the laboratory in the morning after a light breakfast. They were placed in the supine position and fitted with intravenous cannulas and the other measuring devices. After 30 minutes of supine rest, a blood sample was drawn for plasma renin activity (PRA), arginine vasopressin (AVP), atrial natriuretic peptide (ANP), and brain natriuretic peptide (BNP) assays, and sphygmomanometric blood pressure measurements were obtained

Blood samples for ANP and BNP were extracted with SepPak C18 columns (Waters, Milford, Massachusetts, USA) and assessed with radioimmunoassays (Peninsula Laboratories Inc, Belmont, California, USA). The intra- and interassay variation coefficients were $3 \%$ and $12 \%$, respectively, for ANP, and $4 \%$ and $10 \%$, respectively, for BNP. PRA measurement was done using a commercial kit (Sorin Biomedica, Milan, Italy) and expressed as ng angiotensin I per ml of plasma per hour of incubation. Blood samples for AVP were extracted with Sep-Pak C18 columns (Waters) and assessed with radioimmunoassays (Peninsula Laboratories). The assays of ANP, BNP, PRA, and AVP were done in plasma samples as previously described. ${ }^{21}$

\section{Deactivation and stimulation of cardiopulmonary receptors}

All studies were carried out in a quiet, temperature controlled room at $22-24^{\circ} \mathrm{C}$. Deactivation of cardiopulmonary receptors was obtained by LBNP as previously described. ${ }^{22}$ Briefly the subjects were fitted into a fibreglass box sealed at the level of the iliac crests and underwent three 15 minute periods of LBNP in a randomised order $(-7,-14$, and $-20 \mathrm{~mm} \mathrm{Hg})$, each followed by a 30 minute period of rest. Blood pressure, central venous pressure (CVP), heart rate, and forearm blood flow were determined, and vascular resistances were calculated every five minutes during each experimental period.

Stimulation of cardiopulmonary receptors was obtained by increasing venous return through passive raising of the legs and the lower part of the pelvis to $60^{\circ} .^{11}$

\section{Cold pressor test}

The cold pressor test involved immersion of one hand in ice cold water $\left(4^{\circ} \mathrm{C}\right)$ for two minutes to determine whether alteration in responses to LBNP was the result of a nonspecific change in neurogenic control. Values of forearm vascular resistance before and at the end of cold stimulus were compared.

\section{Haemodynamic measurements}

Arterial blood pressure was monitored in all subjects with an automatic oscillometer cuff sphygmomanometer (Dynamap, Critikon, Tampa, Florida, USA). Reliability of measurement was initially checked in all patients with a mercury sphygmomanometer, the first and fifth Korotkoff sounds being taken to identify systolic and diastolic values, respectively.

CVP was measured by a pressure transducer connected to a catheter inserted into an antecubital vein. ${ }^{23}$ Heart rate was monitored continuously by a cardiotachometer triggered by the R wave of an ECG lead.

Forearm blood flow was measured by venous occlusion strain gauge plethysmography (Microlab Elettronica, Padova, Italy). The pressure in the venous occlusion or congesting cuff at the upper arm was $50 \mathrm{~mm} \mathrm{Hg}$. The strain gauge was placed approximately $5 \mathrm{~cm}$ below the antecubital crease. Hand blood flow was cut off by placing a cuff around the 
wrist and inflating it above systolic pressure during measurements. Forearm blood flow was taken as the average of four to eight flow measurements made at 15 second intervals. Forearm vascular resistance was calculated by dividing mean arterial pressure (in $\mathrm{mm} \mathrm{Hg}$ ) by forearm blood flow, and was expressed in units $(\mathrm{mm} \mathrm{Hg} / \mathrm{ml} / 100 \mathrm{~g} / \mathrm{min})$.

\section{Calculations and statistical analysis}

All data are expressed as mean (SD).

The efficiency of cardiopulmonary baroreceptor reflex for each subject was expressed as the slope (gain) of the linear regression obtained by plotting the changes in forearm vascular resistance against the corresponding changes in CVP induced by the application of graded degrees of LBNP $(0,-7$, and $-14 \mathrm{~mm} \mathrm{Hg})$ and leg raising. ${ }^{24}$

The individual values of each variable obtained under baseline conditions and in response to the different stimuli were compared using analysis of variance for repeated measurements and Student's $t$ test for paired data. Comparison between groups was done using a one way analysis of variance and Student's $t$ test followed by Tukey's multiple range comparison test, as appropriate. Univariate linear relations were analysed by Pearson correlation.

For multivariate re-evaluation of univariate correlations the following were entered in a stepwise multiple regression analysis as independent variables: left atrial diameter, septum and posterior wall thickness, relative wall thickness, left ventricular systolic and diastolic dimensions, left ventricular mass, end systolic stress, left ventricular ejection fraction, fractional shortening, mean velocity of circumferential fibre shortening, and E/A ratio; cardiopulmonary reflex gain and the six minute walk test were the dependent variables. The significance level for univariate and multivariate testing was set at 0.05 . All calculations were done with BMDP statistical software.

\section{RESULTS}

\section{Subject characteristics}

Clinical and haemodynamic baseline characteristics of subjects investigated are reported in table 1. A similar left ventricular wall thickness was found in the three groups, but the patients had higher left atrial and ventricular internal diameters and left ventricular mass than the controls (table 1). Left ventricular ejection fraction and contractility index (Vcf) were reduced in both patient groups.

The mean values of PRA, AVP, and natriuretic peptides are reported in table 1. Circulating concentrations of PRA and AVP were not significantly different among the three groups, whereas plasma ANP and BNP were higher $(\mathrm{p}<0.05)$ in NYHA class II patients than in controls or NYHA class I patients (table 1).

The mean distances walked by normal subjects and by patients with class I and class II heart failure were 502 (50) m, 465 (57) m, and 391 (64) m, respectively. There were significant differences between the distance walked by class II patients and by subjects in the control and class I groups $(\mathrm{p}<0.01)$, though there was overlap between controls and class I patients (fig 1A).

\section{Haemodynamic response to cardiopulmonary receptor unloading and loading}

Haemodynamic changes plateaued five minutes after the application of LBNP in all groups, remaining steady during the following 15 minutes. In controls, LBNP of $-7 \mathrm{~mm} \mathrm{Hg}$ and $-14 \mathrm{~mm} \mathrm{Hg}$ caused significant stepwise reductions in forearm blood flow and increases in forearm vascular resistance, with no significant changes in heart rate or systolic, diastolic, and pulse pressure. Conversely the application of $-20 \mathrm{~mm} \mathrm{Hg}$ resulted in a mild but significant increase in heart rate, indicating the interference of the aortic baroreflex. We therefore limited the range of LBNP to the low level suction ( 0 to $-14 \mathrm{~mm} \mathrm{Hg}$ ) in all the following analyses in both controls and patients.

Figure 2 shows the similar effects of the application of LBNP on CVP in the three groups, together with the corresponding changes in forearm blood flow and vascular resistance. In all groups the application of LBNP decreased CVP to the same degree, thus confirming a similar unloading effect on central blood volume.

In NYHA class I patients the haemodynamic response of forearm blood flow and forearm vascular resistance to $-14 \mathrm{~mm}$ Hg LBNP was significantly reduced versus controls $(p<0.01)$ (fig 2, table 2). Conversely the response to cardiopulmonary receptor stimulation mediated by the CVP increase during leg raising resulted in an increase in forearm blood flow and a reduction in forearm vascular resistance that was not significantly different from controls (fig 2).

The tonic activity of the cardiopulmonary receptor system was further reduced in NYHA class II patients because the preload reduction following the application of LBNP at -7 and $-14 \mathrm{~mm} \mathrm{Hg}$ caused impaired forearm blood flow and forearm vascular resistance responses (table 2, fig 2). NYHA class II patients also showed a reduced sensitivity of the cardiopulmonary reflex to preload increase (table 2).

The efficiency of the cardiopulmonary baroreflex function, illustrated by the relation between the CVP changes and the

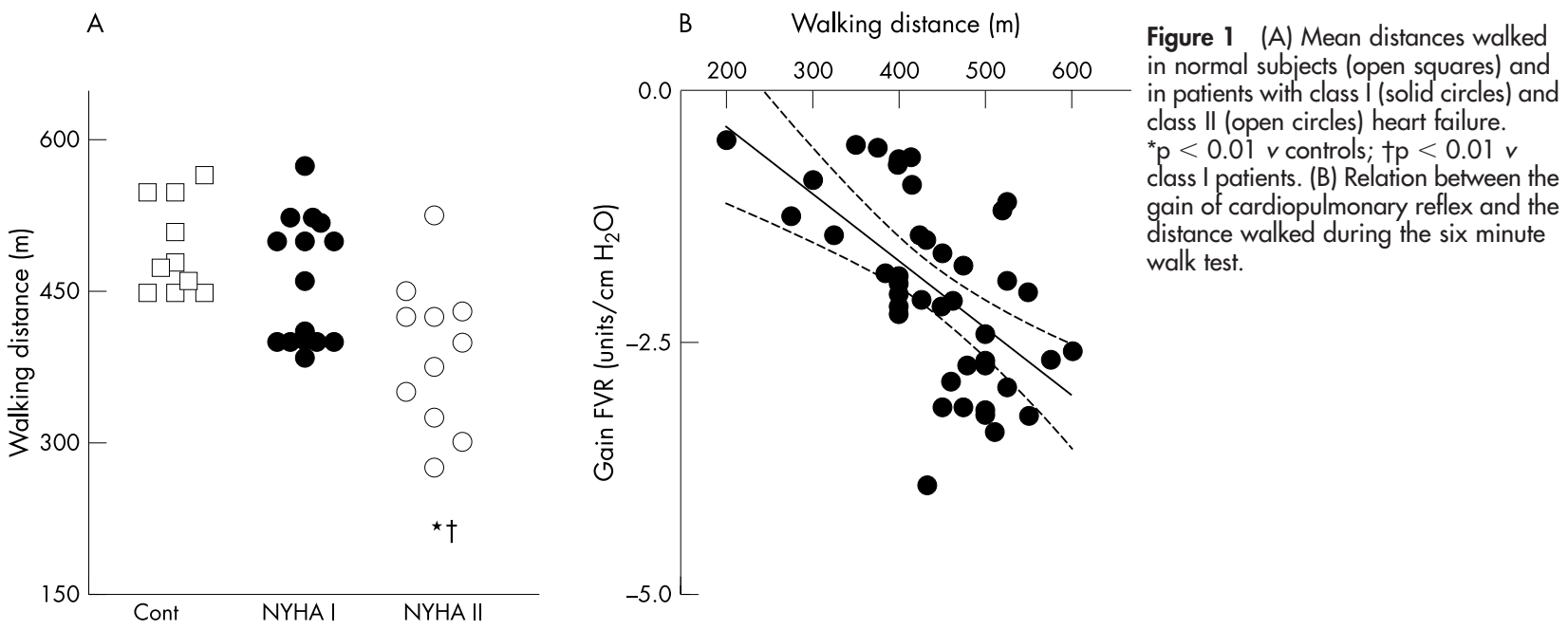



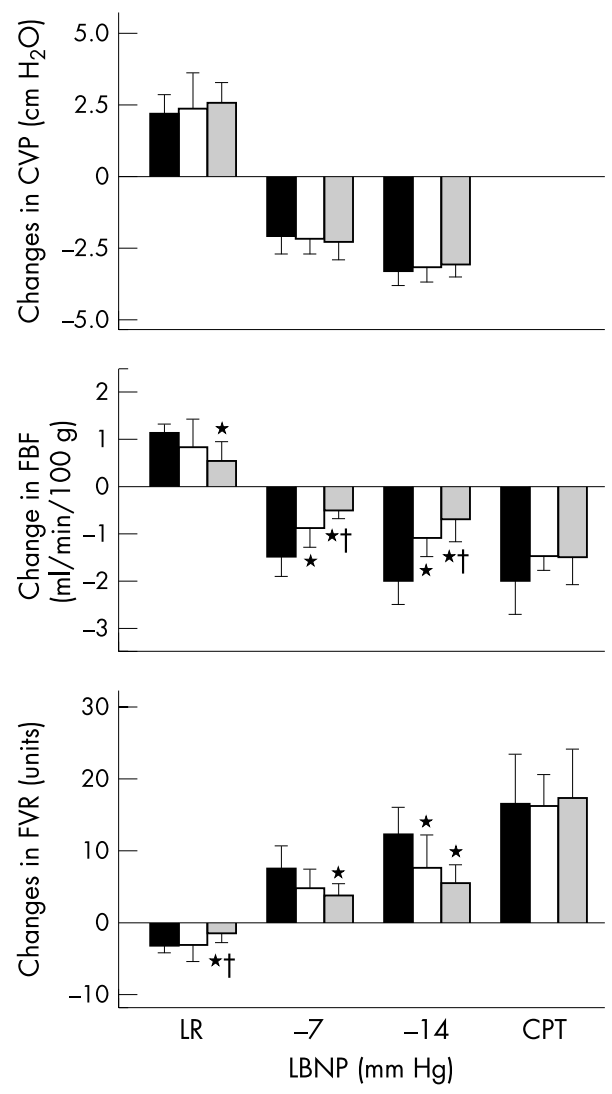

Figure 2 Changes in central venous pressure (CVP), forearm blood flow (FBF), and forearm vascular resistance (FVR) during leg raising (LR), lower body negative pressure (LBNP) at -7 and $-14 \mathrm{~mm} \mathrm{Hg}$, and cold pressor test (CPT) in controls (solid bars), NYHA class I heart failure (open bars), and NYHA class II heart failure (grey bars). ${ }^{*} p<0.01 v$ controls; $\uparrow p<0.01 v$ class I patients.

corresponding changes of calculated forearm vascular resistance, is shown in fig 3, using observations at baseline, -7 ,

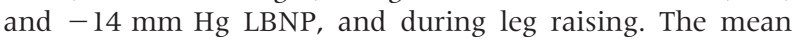

slope of each individual CVP-forearm vascular resistance regression line (gain of the reflex system) was significantly different between groups $(-2.78(0.66)$ in controls $v-1.99$ $(0.83)$ in NYHA class I patients $(p<0.05)$, and $-1.29(0.5)$ in NYHA class II patients $(p<0.001))$. The gain of the cardiopulmonary reflex was significantly related to the distance walked during the six minute corridor test (fig 1B).

When all patients were considered as a whole, multivariate stepwise regression analysis showed that the efficiency of the cardiopulmonary reflex was independently related only to the $\mathrm{E} / \mathrm{A}$ ratio $(\mathrm{F}=8.6 ; r=-0.48)$ (table 3$)$.

Conversely multivariate stepwise regression analysis selected the gain of the cardiopulmonary reflex $(\mathrm{F}=14.3)$ as the most predictive variable, and left atrial diameter $(\mathrm{F}=12)$, and pulmonary pressure $(\mathrm{F}=4.2)$ as independent variables for the distance walked during the six minute corridor test (multiple regression, $r=0.77$ ).

\section{Cold pressor test}

In both patient groups the cold pressor test caused a significant reduction in forearm blood flow and an increase in vascular resistance with no differences in comparison with the controls (fig 2).

\section{DISCUSSION}

Our findings show first, that in patients at the earliest stage of heart failure (NYHA class I) the cardiopulmonary reflex system exerts a reduced tonic restraint on sympathetic efferent activity to the peripheral vessels, whereas the acute vasodilator response to preload increase is preserved; second, that the onset of the reduced vasodilator response to a preload increase occurs in conjunction with mild limitation of physical activity (NYHA class II patients); and third, that when all the patients are considered together, cardiopulmonary reflex sensitivity is the most predictive independent variable for effort tolerance in mild heart failure.

\section{Reduced cardiopulmonary baroreceptor sensitivity in mild heart failure}

Both cardiopulmonary and arterial baroreceptor reflex sys tems are reported to be impaired in severe heart failure, ${ }^{12-15}$

\begin{tabular}{|c|c|c|c|c|c|}
\hline & \multirow[b]{2}{*}{ Baseline } & \multirow[b]{2}{*}{ Raised legs } & \multicolumn{2}{|l|}{ LBNP } & \multirow[b]{2}{*}{ Gain } \\
\hline & & & $-7 \mathrm{~mm} \mathrm{Hg}$ & $-14 \mathrm{~mm} \mathrm{Hg}$ & \\
\hline $\begin{array}{l}\text { Controls } \\
\text { CVP }\left(\mathrm{cm} \mathrm{H} \mathrm{H}_{2} \mathrm{O}\right) \\
\text { MAP }(\mathrm{mm} \mathrm{Hg}) \\
\text { Heart rate }(\text { beats } / \mathrm{min}) \\
\text { FBF }(\mathrm{ml} / \mathrm{min} / 100 \mathrm{~g}) \\
\text { FVR (U) }\end{array}$ & $\begin{array}{l}1.8(0.5) \\
90(7) \\
72(9) \\
5.2(0.8) \\
17.8(3.9)\end{array}$ & $\begin{array}{l}5.2(1.4) \\
88(7) \\
73(7) \\
5.9(0.9) \\
15.4(3.6)\end{array}$ & $\begin{array}{l}-0.1(0.9) \\
89(9) \\
74(7) \\
3.7(0.6) \\
24.9(6.4)\end{array}$ & $\begin{array}{l}-1.2(0.6) \\
90(9) \\
77(8) \\
2.8(0.4) \\
33.6(7.3)\end{array}$ & $-2.78(0.66)$ \\
\hline $\begin{array}{l}\text { NYHA class I } \\
\text { CVP }\left(\mathrm{cm} \mathrm{H}_{2} \mathrm{O}\right) \\
\text { MAP }(\mathrm{mm} \mathrm{Hg}) \\
\text { Heart rate }(\text { beats } / \mathrm{min}) \\
\text { FBF }(\mathrm{ml} / \mathrm{min} / 100 \mathrm{~g}) \\
\text { FVR (U) }\end{array}$ & $\begin{array}{l}1.6(0.7) \\
93(9) \\
67(4) \\
4.6(1.1) \\
21.4(5.4)\end{array}$ & $\begin{array}{l}4.7(1.6) \\
94(12) \\
67(6) \\
5.2(1.1) \\
18.9(4.6)\end{array}$ & $\begin{array}{l}-0.6(1.1) \\
93(10) \\
70(5) \\
3.7(1.1) \\
27.5(8.0)\end{array}$ & $\begin{array}{l}-1.5(0.9) \\
92(8) \\
70(5) \\
3.2(1.0) \\
31.9(9.4)\end{array}$ & $-1.99(0.83)^{*}$ \\
\hline $\begin{array}{l}\text { NYHA class II } \\
\text { CVP }\left(\mathrm{cm} \mathrm{H} \mathrm{H}_{2} \mathrm{O}\right) \\
\text { MAP }(\mathrm{mm} \mathrm{Hg}) \\
\text { Heart rate }(\text { beats } / \mathrm{min}) \\
\text { FBF }(\mathrm{ml} / \mathrm{min} / 100 \mathrm{~g}) \\
\text { FVR (U) }\end{array}$ & $\begin{array}{l}2.1(0.6) \\
93(5) \\
72(8) \\
4.2(1.1)^{*} \\
23.6(5.5)^{*}\end{array}$ & $\begin{array}{l}6.1(0.8) \\
94(8) \\
72(9) \\
4.5(0.8)^{*} \\
21.8(4.1)^{*}\end{array}$ & $\begin{array}{l}-0.2(0.6) \\
93(5) \\
73(9) \\
3.7(1.1) \\
27.1(6.1)\end{array}$ & $\begin{array}{l}-1.1(0.6) \\
93(5) \\
75(11) \\
3.2(0.9) \\
27.3(5.6)\end{array}$ & $-1.29(0.5)^{*} \dagger$ \\
\hline
\end{tabular}

${ }^{*} \mathrm{p}<0.05 v$ controls; $\uparrow \mathrm{p}<0.05 v \mathrm{NYHA}$ class $\mathrm{I}$.

CVP, central venous pressure; FBF, forearm blood flow; FVR, forearm vascular resistance; LBNP, lower body negative pressure; MAP, mean arterial blood pressure; NYHA, New York Heart Association. 


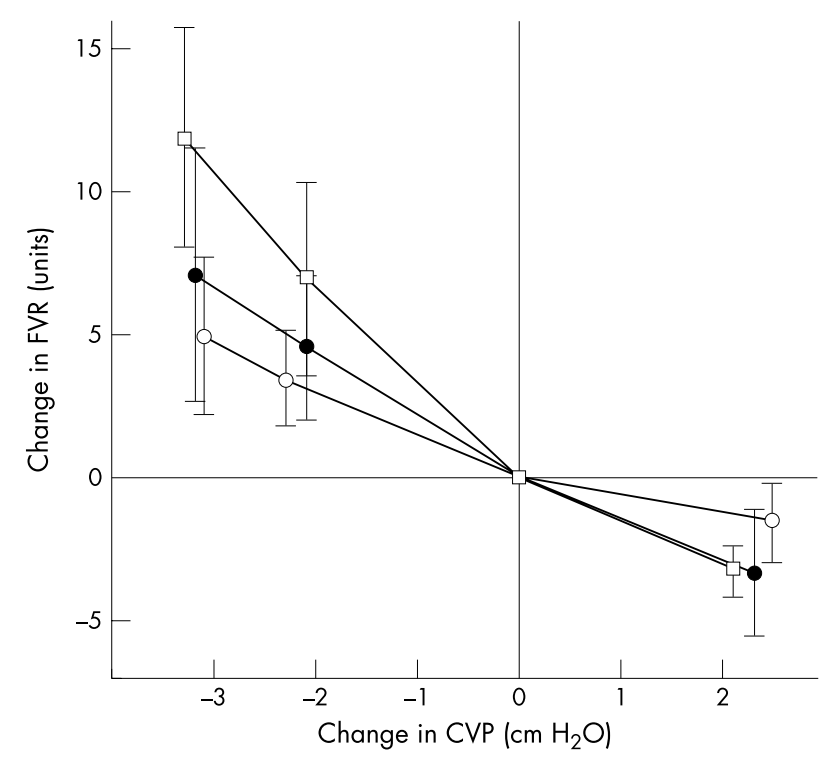

Figure 3 Efficiency of the cardiopulmonary baroreflex function, illustrated by the relation between the central venous pressure (CVP) changes and the corresponding changes of calculated forearm vascular resistance (FVR) using observations at baseline, at -7 and $-14 \mathrm{~mm} \mathrm{Hg}$ LBNP, and during leg raising in normal subjects (open squares), NYHA class I patients (solid circles), and NYHA class II patients (open circles).

whereas at the early stages of the disease only a reduced efficiency of the arterial baroreflex system is found. ${ }^{1}$

Adjustment of reflex vascular resistance to cardiopulmonary baroreceptor deactivation may be investigated noninvasively in humans, using LBNP and peripheral blood flow measurements. Low level suction to the lower body decreases the central blood volume without observable effects on heart rate or mean arterial pressure, and its effect is thus considered to be primarily on the cardiopulmonary baroreflexes. On the other hand, higher levels of negative pressure-which produce a fall in pulse pressure and result in a reflex chronotropic and vasomotor response-affect both cardiopulmonary and arterial baroreflexes. ${ }^{1125}$ To minimise the possible influence of arterial baroreceptors on cardiopulmonary reflex system ${ }^{26}$ we limited the range of LBNP to low level suction ( 0 to $-14 \mathrm{~mm} \mathrm{Hg}$ ), which decreased central blood volume without an observable effect on heart rate or mean blood pressure. In controls the haemodynamic response shows a symmetrical slope for either increase or reduction in CVP within the investigated range, indicating that in normal individuals the setpoint of the reflex is located in the linear part of the baroreflex curve. The peripheral vasoconstriction following preload reduction unmasks restraint on sympathetic outflow of the tonic physiological cardiopulmonary reflex, while the vasodilator response to leg raising is an expression of the acute phasic activity of the system. The altered haemodynamic response to receptor downloading in our NYHA class I heart failure patients reveals a reduced tonic inhibitory effect of cardiopulmonary reflex system on sympathetic outflow at rest. However, in NYHA class I patients the acute vasodilator response to preload increase is preserved. Therefore these patients have reduced tonic activity at rest, notwithstanding the fact that the system still responds to acute preload increase. This pattern of response seems to indicate that the setpoint of the mechanoceptor reflex is shifted to the lower left part of the curve ${ }^{27}$ in the direction of hypovolaemia, in spite of the fact that resting levels of CVP did not differ between the controls and the heart failure patients.
Patients with a mild limitation of physical activity (NYHA class II) have an impaired forearm vascular resistance response to both preload increase and preload reduction, with a reduced maximal power of the reflex system, which indicates definitive resetting. The reduction in the tonic inhibitory influence of the cardiopulmonary reflex system on the sympathetic nervous system would tend to favour the development of a neurohumoral excitatory state with onset of sympathetically mediated vasoconstriction. The role of the cardiopulmonary baroreceptors in regulating extracellular fluid volume has been challenged by Gilmore, ${ }^{28}$ but an altered arterial baroreflex response to volume infusion was reported to be associated with reduced sodium excretion in patients with mild heart failure. ${ }^{29}$ The reduced restraint on the sympathetic outflow may thus contribute to activating sodium retention mechanisms that indirectly favour fluid retention and hypervolaemia. In the present study only plasma concentrations of natriuretic peptides (ANP and BNP) were increased in class II patients, while plasma renin activity and AVP were not significantly different from controls. However, early activation of the local renal and cardiac autocrine/paracrine systems is now a well recognised feature of heart failure in the absence of systemic activation. ${ }^{2}{ }^{30-32}$

Table 3 Univariate and stepwise multiple regression between $(A)$ the gain of cardiopulmonary reflex and haemodynamic variables, and (B) between the results of the walk test and the gain of the cardiopulmonary reflex and other haemodynamic variables

(A) Dependent variable gain of cardiopulmonary reflex:

\begin{tabular}{|c|c|c|}
\hline & \multicolumn{2}{|c|}{ Gain in FVR reflex $\left(\mathrm{U} / \mathrm{cm} / \mathrm{H}_{2} \mathrm{O}\right)$} \\
\hline & $r$ & $\mathrm{p}$ Value \\
\hline $\begin{array}{l}\text { E/A ratio } \\
\text { LVEF }(\%) \\
\text { FS }(\%) \\
\text { ESS }\left(\mathrm{kdyne} / \mathrm{cm}^{2}\right) \\
\text { Vcf }\left(\mathrm{s}^{-1}\right) \\
\text { Left atrium }(\mathrm{mm}) \\
\text { Posterior wall }(\mathrm{mm}) \\
\text { LVM }(\mathrm{g}) \\
\text { Septum }(\mathrm{mm}) \\
\text { LVSD }(\mathrm{mm}) \\
\text { LVDD }(\mathrm{mm}) \\
\text { RWT }\end{array}$ & $\begin{array}{r}-0.48^{*} \\
-0.37 \\
0.02 \\
0.18 \\
-0.13 \\
-0.20 \\
0.10 \\
0.10 \\
0.04 \\
0.03 \\
0.05 \\
-0.03\end{array}$ & $\begin{array}{l}0.01 \\
0.01 \\
- \\
- \\
- \\
- \\
- \\
- \\
- \\
- \\
- \\
-\end{array}$ \\
\hline \multicolumn{3}{|c|}{ (B) Dependent variable walk corridor test: } \\
\hline & \multicolumn{2}{|c|}{ Walk corridor test $(\mathrm{m})$} \\
\hline & $r$ & $\mathrm{p}$ Value \\
\hline $\begin{array}{l}\text { Gain in FVR reflex }(\mathrm{U} / \mathrm{mm} \mathrm{Hg}) \\
\text { LVEF }(\%) \\
\text { Posterior wall }(\mathrm{mm}) \\
\text { Left atrium }(\mathrm{mm}) \\
\text { LVM }(\mathrm{g}) \\
\text { Vcf }\left(\mathrm{s}^{-1}\right) \\
\text { FS }(\%) \\
\text { ESS }\left(\mathrm{kdyne} / \mathrm{cm}^{2}\right) \\
\text { LVSD }(\mathrm{mm}) \\
\text { LVDD }(\mathrm{mm}) \\
\text { E/A ratio } \\
\text { Septum }(\mathrm{mm}) \\
\text { RWT }\end{array}$ & $\begin{array}{l}-0.57^{*} \\
0.47 \\
-0.39^{*} \\
-0.33^{*} \\
-0.30 \\
0.29 \\
0.26 \\
-0.26 \\
-0.24 \\
-0.16 \\
0.13 \\
-0.02 \\
-0.01\end{array}$ & $\begin{array}{l}0.01 \\
0.01 \\
0.01 \\
0.05 \\
- \\
- \\
- \\
- \\
- \\
- \\
- \\
- \\
-\end{array}$ \\
\hline
\end{tabular}

*Independent variables at stepwise regression analysis. $E / A$ ratio, ratio of early maximum $(E)$ to atrial $(A)$ left ventricular filling inflow velocity; ESS, end systolic stress; FBF, forearm blood flow; FS, fractional shortening; FVR, forearm vascular resistance; LVDD, left ventricular diastolic diameter; LVEF, left ventricular ejection fraction; LVM, left ventricular mass; LVSD, left ventricular systolic diameter; RWT, relative wall thickness; Vcf, mean velocity of circumferential fibre shortening. 
A non-specific depression of vascular responsiveness to neural stimuli can be ruled out because in the patients with heart failure the vasoconstrictor response to the cold pressor test was normal. Thus the reflex impairment appears to be related to an alteration in the afferent branch.

\section{Role of myocardial stiffness}

Stepwise regression analysis of our data showed that the reduced cardiopulmonary reflex sensitivity in the early phase of heart failure was related to an index of reduced compliance, the E/A ratio. Reduced compliance of the cardiac chamber has been reported to play a role in the sensitivity of the cardiopulmonary reflex system. ${ }^{33}$ However, our patients with heart failure all met the definition of the European Society of Cardiology. ${ }^{16}$ None showed echocardiographic evidence of concentric hypertrophy, and patients with primary diastolic heart failure attributable to hypertension, valvar heart disease, cor pulmonale, or restrictive cardiomyopathy were excluded. Despite these exclusions, it is now recognised that a majority of patients with heart failure have diastolic dysfunction of varying degree, and previous studies have shown that the impairment of cardiomyocyte relaxing properties is an early event in heart failure. ${ }^{34}$ The arrangement of cardiac mechanoceptors parallel to muscle fibres during cardiac remodelling could be responsible for the decreased sensitivity of the cardiac mechanoceptors in patients with increased myocardial stiffness. In fact, cardiopulmonary receptors appear to respond to stretch rather than to pressure changes. In the presence of reduced chamber compliance a similar reduction in pressure may be associated with a lesser change in stretch. An acute impairment of the cardiopulmonary reflex system was reported one month after acute myocardial infarction, even before the development of cardiac remodelling. ${ }^{35}$ Present findings extend this observation, indicating that the mild reduction in cardiopulmonary reflex gain that persists after myocardial infarction represents an important index of limitation of functional capacity.

\section{Pathophysiological implications}

An important observation of the present study is that the impaired cardiopulmonary reflex sensitivity represents the most predictive independent variable for functional capacity in patients with mild heart failure. It is well recognised that the severity of symptomatic exercise limitation varies between patients, with little relation to the extent of left ventricular systolic dysfunction at rest or to markers of central haemodynamic disturbance. Present findings indicate that, compared with age matched controls, subjects in class I-II heart failure have impaired sensitivity of the cardiopulmonary reflex system. The transition from NYHA class I to II, which is characterised by the onset of clinical symptoms in ordinary physical activities, coincides with a blunted vasodilator response to acute preload increase. Indeed when all the subjects were considered as a whole, multivariate analysis indicated that the impaired capacity to adjust the peripheral circulation to a preload increase might play a role in reducing effort tolerance in the corridor walking test. The diversion of blood flow away from the muscles during exercise, which has been reported to contribute to exercise intolerance in patients with chronic heart failure, ${ }^{36}$ might therefore also contribute to muscle fatigue in the early phase of the disease. ${ }^{37}$ In addition, cardiopulmonary baroreflex dysfunction could limit the afterload reduction during exercise.

The relation between cardiopulmonary baroreflex gain and functional capacity applied even to the control group. This raises the alternative possibility that in healthy controls and patients with "early" heart failure, fitness may have altered the gain of the cardiopulmonary reflex when compared with class II patients. Physical training is known to improve the clinical status of patients with heart failure by improving arterial baroreflexes and the metabolism, function, and endurance of skeletal muscle, as well as endothelial function in the peripheral circulation. ${ }^{38}$ Though this possibility cannot be excluded, it should be borne in mind that no subject in the present study was involved in a programme of physical training (recreational or professional) and all were sedentary.

An impaired cardiopulmonary reflex mediated capacity to adjust the peripheral circulation to a preload increase might be insufficient to account for the time course and magnitude of the adrenergic activation in advanced heart failure, where other mechanisms - such as a metabolic reflex arising from skeletal muscle ${ }^{39}$ and a direct sympatho-excitatory effect of increased cardiac filling pressure ${ }^{40}$ - could play a role.

\section{CONCLUSIONS}

Our findings support the role of a primary cardiac alteration in determining the changes to the peripheral circulation that finally limit exercise in heart failure, rather than the heart dysfunction that initiated the syndrome.

\section{ACKNOWLEDGEMENTS}

The financial support of the Ministero dell'Universita' e della Ricerca Scientifica e Tecnologica, Rome, Italy (project "Heart Failure" No 9506103918), and the University of Florence (60\% funding, 1999) is gratefully acknowledged.

\section{Authors' affiliations \\ P A Modesti, G Polidori, I Bertolozzi, S Vanni, I Cecioni, Clinica Medica e Cardiologia, University of Florence, Florence, Italy}

\section{REFERENCES}

1 Grassi G, Seravalle G, Cattaneo BM, et al. Sympathetic activation and loss of reflex sympathetic control in mild congestive heart failure. Circulation 1995;92:3206-11.

2 Rundqvist B, Elam M, Bergmann-Sverrisdottir Y, et al. Increased cardiac adrenergic drive precedes generalized sympathetic activation in human heart failure Circulation 1997:95:169-75.

3 Francis GS, Benedict C, Johnstone DE, et al. Comparison of neuroendocrine activation in patients with left ventricular dysfunction with and without congestive heart failure. A substudy of the studies of left ventricular dysfunction (SOLVD). Circulation 1990:82:1724-9.

4 Swedberg K, Eneroth P, Kjekshus J, et al. For the CONSENSUS Trial Study Group. Hormones regulating cardiovascular function in patients with severe congestive heart failure and their relation to mortality. Circulation 1990:82:730-6.

5 Ferguson DW, Berg WJ, Sanders JS. Clinical and hemodynamic correlates of sympathetic nerve activity in normal humans and patients with heart failure: evidence from direct microneurographic recordings. J Am Coll Cardiol 1990; 16:1125-34

6 Mark AL. Sympathetic dysregulation in heart failure: mechanisms and therapy. Clin Cardiol 1995; 18:13-8.

7 Abboud FM, Meistad DD, Mark Al, et al. Reflex control of the peripheral circulation. Prog Cardiovasc Dis 1976;18:371-403.

8 Vallbo AB, Hagbarth KE, Torebjork HE, et al. Somatosensory, proprioceptive, and sympathetic activity in human peripheral nerves. Physiol Rev 1979:59:919-57.

9 Wallin G. Intraneural recording and autonomic function in man. In: Bannister R, eds. Autonomic failure. London: Oxford University Press, 1983:36-51.

10 Hainsworth R. Reflexes from the heart. Physiol Rev 1991;71:617-58.

11 Mark AL, Mancia G. Cardiopulmonary baroreflexes in humans. In: Shepherd JT, Abboud FM, eds. Handbook of physiology, the cardiovascular system. Bethesda MD: Williams and Wilkins, 1983:795-813.

12 Ferguson DW, Abboud FM, Mark AL. Selective impairment of baroreflexmediated vasoconstrictor responses in patients with ventricular dysfunction. Circulation 1984;69:451-60.

13 Mohanty PK, Arrowood JA, Ellenbogen KA, et al. Neurohumoral and hemodynamic effects of lower body negative pressure in patients with congestive heart failure. Am Heart J 1989;1 18:78-85.

14 Creager MA, Hirsch AT, Dzau VJ, et al. Baroreflex regulation of regional blood flow in congestive heart failure. Am J Physiol 1990;258:H1409-14.

15 Dibner-Dunlab ME, Thomas MD. Control of sympathetic nerve activity by vagal mechanoreflexes is blunted in hearth failure. Circulation 1992:86:1929-34.

16 Guidelines for the diagnosis of heart failure. The task force on heart failure of the European Society of Cardiology. Eur Heart J 1995;16:741-51.

17 The Criteria Committee of the New York Heart Association. Nomenclature and criteria for diagnosis of diseases of the heart and great vessels, 9th ed. Boston, Massachusetts: Little, Brown, 1994:253-6. 
18 Henry WL, DeMaria A, Gramiak R, et al. Report of the American Society of Echocardiography nomenclature and standards in two-dimensional echocardiography. Circulation 1980;62:212-21.

19 Nishimura RA, Callahan MJ, Schaff HV, et al. Non invasive measurement of cardiac output by continuous wave Doppler echocardiography. Mayo Clin Proc 1984;59:484-9.

20 Guyatt GH, Sullivan MJ, Thompson PJ, et al. The 6-minute walk: a new measure of exercise capacity in patients with chronic heart failure. Can Med Assoc J 1985; 132:919-23.

21 Neri Serneri GG, Cecioni I, Migliorini A, et al. Both plasma and renal endothelin-1 participate in the acute cardiovascular response to exercise. Eur J Clin Invest 1997;27:761-6.

22 Modesti PA, Hagi MI, Corsoni V, et al. Impaired adaptation of cardiopulmonary receptors to Western diet in normotensive black immigrants. Am J Hypertens 1999; 12:145-50.

23 Gaver $\mathrm{OH}$, Sieker HD. The continuous recording of central venous pressure changes from an arm vein. Circ Res 1956;4:74-8

24 Sagawa K. Concerning "gain". Am J Physiol 1978;235:H1 17.

25 Wieling $\mathrm{W}$, Wesseling $\mathrm{KH}$. Importance of reflexes in the circulatory adjustments to postural changes. In: Hainsworth R, Makt AL, eds. Cardiovascular reflex control in health and disease. London: WB Saunders, 1993.

26 Mack GW, Shi XG, Nose H, et al. Diminished baroreflex control of forearm vascular resistance in physically fit humans. J Appl Physiol 1987:63:105-10.

27 Abboud FM, Thames MD. Interaction of cardiovascular reflexes in circulatory control. In: Shepherd JT, Abboud FM, eds. Handbook of physiology. The cardiovascular system. Peripheral circulation and organ blood flow. Bethesda, Maryland: Williams and Wilkins, 1983:675-753.

28 Gilmore JP. Neural control of extracellular volume in the human and nonhuman primate. In: Shepherd JT, Abboud FM, eds. Handbook of physiology. The cardiovascular system. Peripheral circulation and organ blood flow. Bethesda Maryland: Williams and Wilkins, 1983:885-915.
29 Spinelli L, Petretta M, Marciano F, et al. Cardiac autonomic responses to volume overload in normal subjects and in patients with dilated cardiomyopathy. Am J Physiol 1999;277:H1361-8.

30 Hasking GJ, Esler MD, Jennings GL, et al. Norepinephrine spillover to plasma in patients with congestive heart failure: evidence of increased overall and cardiorenal sympathetic nervous activity. Circulation 1986;73:615-21.

31 Neri Serneri GG, Boddi M, Cecioni I, et al. Cardiac angiotensin II formation in the clinical course of heart failure and its relationship with left ventricular function. Circ Res 2001;88:961-8.

32 Modesti PA, Cecioni I, Costoli A, et al. Renal endothelin in heart failure and its relation to sodium excretion. Am Heart J 2000;140:617-22.

33 Grassi G, Giannattasio C, Cleroux J, et al. Cardiopulmonary reflex before and after regression of left ventricular hypertrophy in essential hypertension. Hypertension 1988;12:227-37.

34 Del Monte F, O'Gara P, Poole-Wilson PA, et al. Cell geometry and contractile abnormalities of myocytes from failing human left ventricle. Cardiovasc Res 1995;30:281-90.

35 Grassi G, Giannattasio C, Seravalle G, et al. Cardiopulmonary receptor and arterial baroreceptor reflexes after acute myocardial infarction. Am J Cardiol 1992;69:873-8

36 Wilson JR, Martin JL, Schwartz D, et al. Exercise intolerance in patients with chronic heart failure: role of impaired nutritive flow to skeletal muscle. Circulation 1984;69:1079-87.

37 Drexler $\mathrm{H}$, Coats AJ. Explaining fatigue in congestive heart failure. Annu Rev Med 1996;47:241-56.

38 Coats AJ, Adamopoulos S, Meyer TE, et al. Effects of physical training in chronic heart failure. Lancet 1990;335:63-6.

39 Notarius CF, Atchison DJ, Floras JS. Impact of heart failure and exercise capacity on sympathetic response to handgrip exercise. Am J Physiol Heart Circ Physiol 2001 ; 280:H969-76.

40 Floras JS. Arterial baroreceptor and cardiopulmonary reflex control of sympathetic oufflow in human heart failure. Ann NY Acad Sci $2001: 940: 500-13$.

\section{IMAGES IN CARDIOLOGY}

\section{Electron beam tomography of an interpulmonary saddle embolus}

A 63 year old woman with a history of gastrectomy for gastric cancer and locally recurrent and metastatic disease presented to the ER with progressive shortness of breath and left sided chest pain. At physical examination the patient had a heart rate of $84 /$ min and was mildly tachypnoeic. The ECG was normal. At Doppler ultrasound the patient had bilateral deep venous thrombosis (DVT) of the legs. An electron beam tomographic (EBT) study of the chest was performed to rule out pulmonary embolism. The EBT study (panel A) showed a large pulmonary

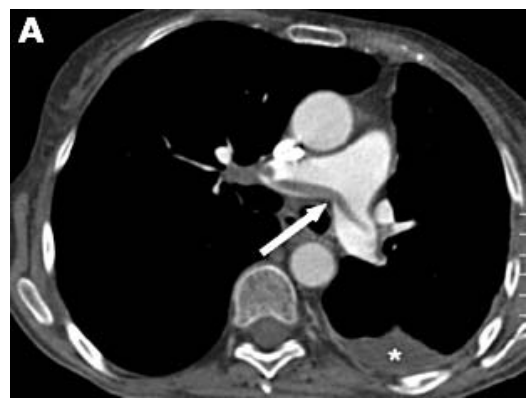

embolus extending across the bifurcation of the main pulmonary artery (PA) into both lungs (interpulmonary saddle embolus; arrow). The volume rendered image (panel B) provides an angioscopic view from the main PA into the right and left PA demonstrating extension of the embolus across the bifurcation of the main PA (straight arrow) into the right lower lobe artery (curved arrow). The right atrium and right ventricle, however, were not dilated which was

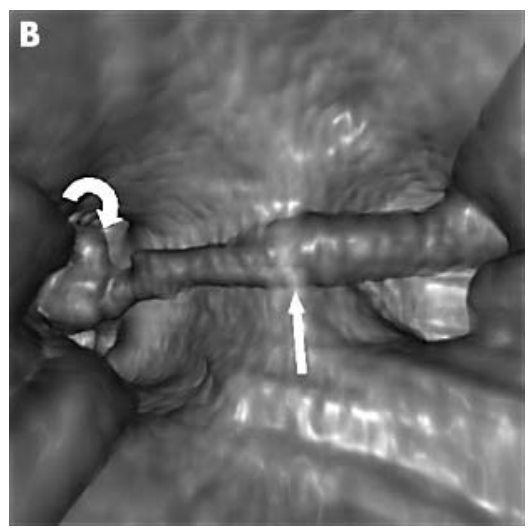

confirmed by echocardiography. There was a pre-existing malignant pleural effusion on the left ( $*$ in panels A and C). Anticoagulation therapy was implemented and clinical symptoms subsequently resolved. A follow up EBT study (panel C) performed 14 days after the initial scan shows complete resolution of the saddle embolus at the level of the main PA.

\section{N H Enzweiler A E Lembcke B Hamm} christian.enzweiler@charite.de

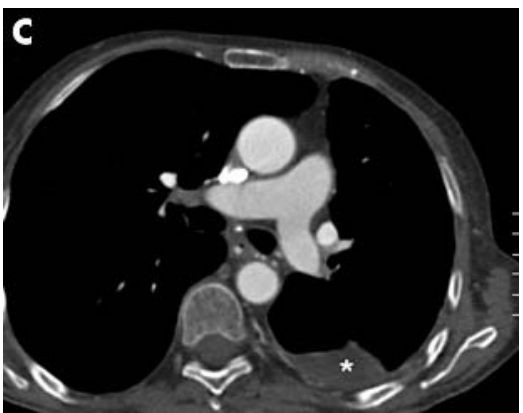

